International Journal of Advancement in Life Sciences Research

Online ISSN: 2581-4877

journal homepage http://ijalsr.org

Original Article

\title{
A Study to Assess the Knowledge Regarding Osteoporosis and Related Fractures among Peri Menopausal Women of Indian Society
}

\author{
Chhanda Pal ${ }^{1 *}$, Smritikana Mani ${ }^{2}$, Ananda Kisor Pal ${ }^{3}$ \\ ${ }^{1}$ PhD Scholar, College of Nursing, Calcutta National Medical College \& Hospitals, Kolkata, West Bengal, India. \\ ${ }^{2}$ Principal \& Professor, College of Nursing, Medical College \& Hospitals, Kolkata, West Bengal, India. \\ ${ }^{3}$ Professor \& Head, Department of Orthopaedics, I.P.G.M.E.R., S.S.K.M. Medical College, Kolkata, West Bengal, \\ India
}

Correspondence E-mail : chhandapal13@gmail.com*

\begin{abstract}
In order to reduce the risk of development of osteoporotic fragility fractures by identification of individuals carrying highest risk factors, we selected 50 perimenopausal women of 40 to 55 years age who attended in orthopaedic OPD in SSKM Hospital, Kolkata, West Bengal, India from September 2019 to November2019 with skeletal pain.

The structured interview schedule was administered to collect the demographic information as well as to assess their knowledge on osteoporosis and related fractures. Then the physical examination proforma was used to assess the height, weight \& BMI of the participants. The descriptive survey design was used with demographic and research variables. The nonprobability purposive samples were selected as per inclusion and exclusion criteria.

In our study, there is significant knowledge deficit among perimenopausal women regarding osteoporosis and resultant fragility fractures irrespective of age and occupation, but associated with lack of conventional education. Significant knowledge deficit (SKD) in 31 patients (62\%) of our samples proves reformation \& improvement of education in multiple ways is urgently needed for definite increase of the knowledge. High priority group has been identified in this significant knowledge deficit (SKD) group, carrying high risk of occurring fragility fracture who need urgent attention. 11 patients $(22 \%)$ had SKD with osteoporosis (BMD as per DEXA more than - 2.5) and abnormal BMl were termed as highest priority group who needed urgent requirement of comprehensive management of osteoporosis. 13 patients who had SKD with osteopenia (BMD as per DEXA between -1 to -2.5 ) and abnormal BMI were termed as moderately priority group who carry relative urgency of treatment. Whereas seven patients who had SKD with normal BMI and osteopenia or normal BMD were termed as low priority group who may be kept under observation prior to initiation of comprehensive management of osteoporosis.
\end{abstract}

Keywords: Osteoporosis, Perimenopausal women, Fragility fracture, Significant knowledge deficit 


\section{Introduction}

Worldwide, osteoporosis causes more than 8.9 million fracture annually, resulting in an Osteoporotic/ fragility fracture in every 3 seconds (Kanis et al. 2006). 1 in 3 women over age 50 (Perimenopausal age) will experience fragility fractures(Melton et al.1998, Kanis et al.2004). Such fracture commonly occurs in forearm, humerus, hip and spine; resulting in challenging situation for the management with huge financial burden for person, family and the society. According to a study conducted by Mithal and Kaur (2013), about 50 million people in India are either osteoporotic ( $\mathrm{T}$ - score lower than -2.5) or have low bone mass ( $\mathrm{T}$ - score between 1.0 to -2.5$)$. While working in the clinical field a large no. clients (approximately 20-30 clients/day) use to attend outpatient department (OPD) with the complaint of skeletal pain in whole body. So if the perimenopausal women have knowledge of osteoporosis, then the fragility fractures may be prevented - this thought triggered us to take up the study. This study was done to assess the knowledge regarding osteoporosis

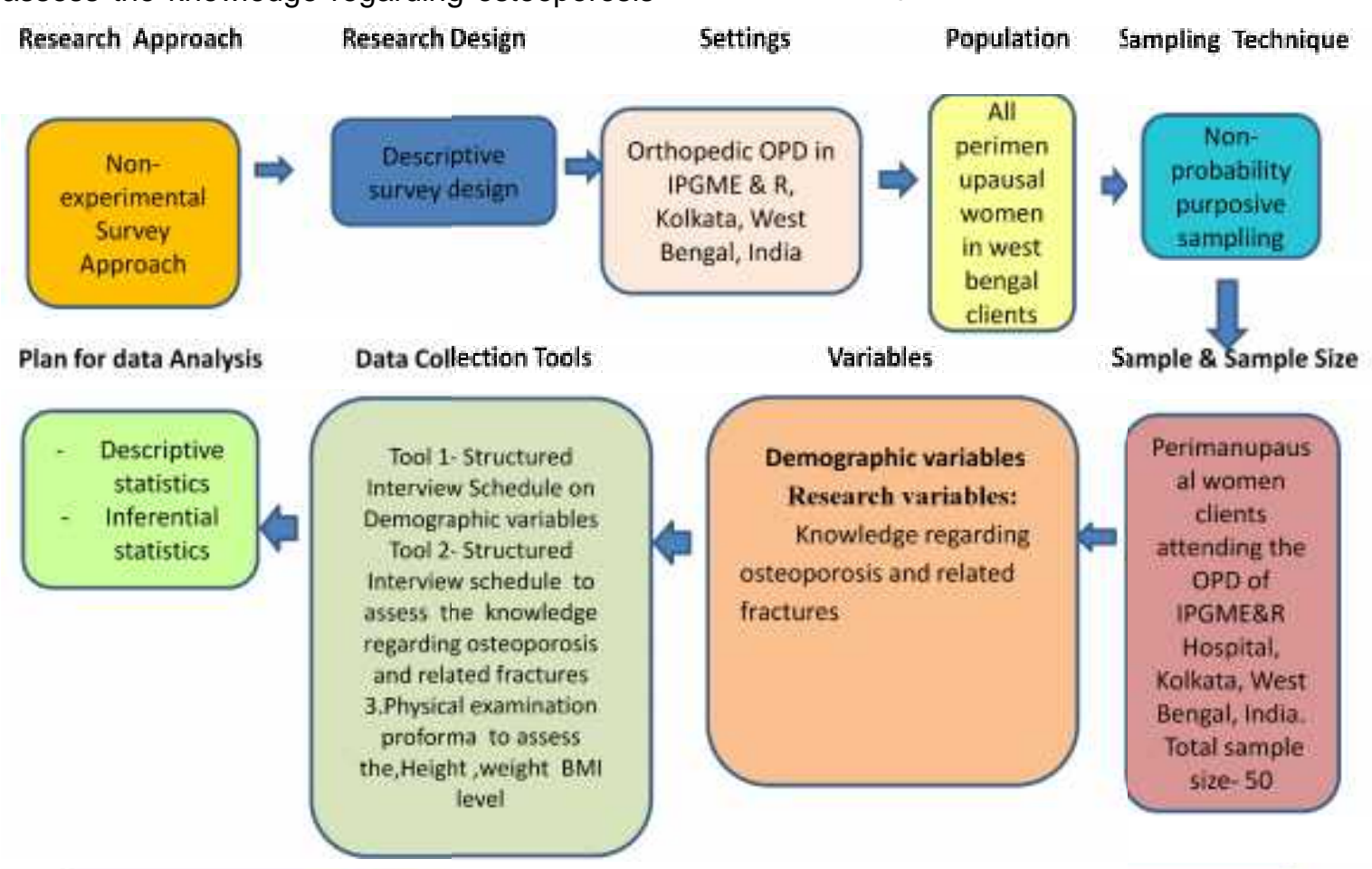

Fig. 1: Schematic Diagram of Research Methodology and related fractures among perimenopausal women of Indian society and to determine the association between selected demographic variables and the knowledge regarding osteoporosis and related fractures among peri menopausal women. Our objectives were extended to identify the risk factors for developing osteoporosis and such fragility fractures among perimenopausal women to identify the at risk individuals who require urgent comprehensive preventive management.

\section{Materials and Methods}

\section{Study design}

\section{Study site:}

Ethical clearance has been obtained from IEC of IPGME\& R Hospital, Kolkata, West Bengal, India. Fifty perimenopausal women of 40 to 55 years age who attended in orthopaedic OPD in SSKM Hospital, Kolkata, West Bengal, India from September 2019 to November 2019 with skeletal pain were selected for the study.

Population Sampling Technique 
Figure. 1 shows Schematic Diagram of Research Methodology
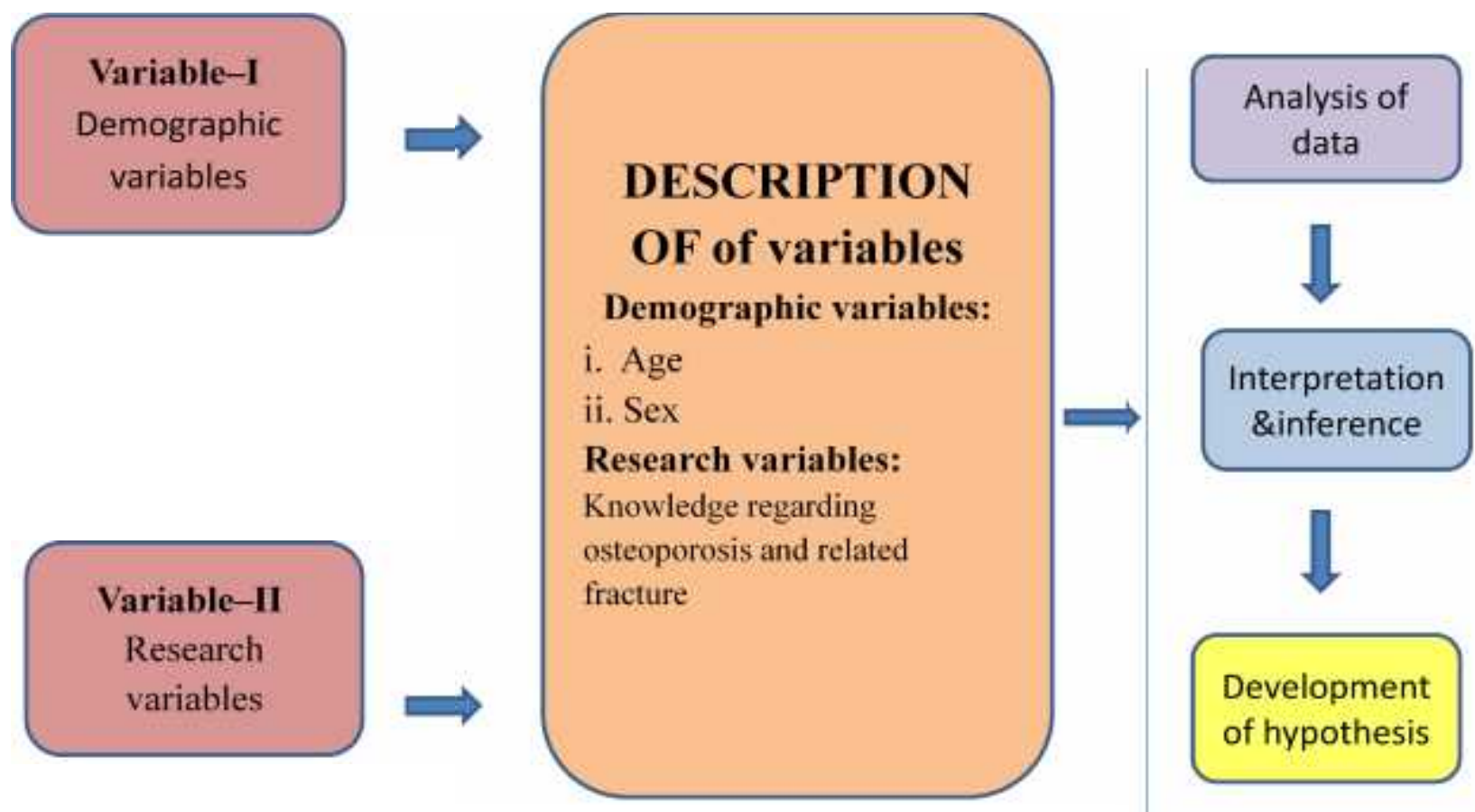

\section{Fig. 2: Schematic Representation of Exploratory Survey Design}

Figure 2 shows Schematic Diagram of Study Design

\begin{tabular}{|l|l|l|l|}
\hline Factors & Frequency & Percentage (\%) & Remarks \\
\hline Age (years) & & & \\
40-45 years & 7 & 14 & $\begin{array}{l}\text { Table shows that majority of perimenopausal } \\
\text { 46-50 years }\end{array}$ \\
$>51$ years & 6 & 74 & $\begin{array}{l}\text { women are 74\% belongs to more than 45 years } \\
\text { of age group. }\end{array}$ \\
\hline Education & & & \\
Secondary & 19 & 38 & Table shows that maximum number of \\
Higher secondary & 16 & 32 & perimenopausal women are belongs Secondary \\
Graduate & 15 & 30 & or bellow secondary background. \\
\hline
\end{tabular}

Table 1 : Frequency percentage distribution of Perimenopausal Women According to age and educational status

\begin{tabular}{|c|c|c|c|}
\hline Occupation & Frequency & Percentage (\%) & Remarks \\
\hline Health ground staff & 23 & $46 \%$ & \multirow{3}{*}{$\begin{array}{l}\text { Table shows that majority of } \\
\text { perimenopausal women }(46 \%) \text { are } \\
\text { Health ground staff }\end{array}$} \\
\hline Housewife & 15 & $30 \%$ & \\
\hline Nursing staff and teacher & 12 & $24 \%$ & \\
\hline \multicolumn{4}{|l|}{ Body Mass Index } \\
\hline Normal & 5 & $10 \%$ & \\
\hline Low & 10 & $20 \%$ & \\
\hline High & 35 & $70 \%$ & $\begin{array}{l}\text { Majority of peri menopausal women }(90 \%) \\
\text { had abnormal BMI. }\end{array}$ \\
\hline
\end{tabular}

Table 2 : Frequency Percentage Distribution of Peri menopausal Women According to Occupation and BMI 
Minimal educational qualification of selected patients who were willing to participate in the study was class VIII and above. Purpose of the study was explained to the subjects. Informed consent was taken for final data collection from participants. Separate code number was given to each selected individual. At first the structured interview schedule was administered to collect the demographic information (Tables 1 \& 2). Then another structured interview schedule was administered to collect the knowledge on osteoporosis and related fractures. Then the physical examination proforma was used to assess the height, weight \& BMI of the participants. Research methodology has been described in Figure 1 where the descriptive survey design was used with demographic and research variable, described in Figure 2. The nonprobability purposive sample were selected as per inclusion criteria as described above. Postmenopausal women were excluded. The variables and technique of their assessment with specific tools were described in Table 3.

\begin{tabular}{|l|l|l|}
\hline Variables & Tools & Techniques \\
\hline 1. Socio-Demographic variables & Tool I : Structured Interview Schedule & Interviewing \\
\hline $\begin{array}{l}\text { 2. Knowledge of osteoporosis and } \\
\text { related fracture }\end{array}$ & Tool II: Structured Interview Schedule & Interviewing \\
\hline 3. BMI Level & $\begin{array}{l}\text { Tool III: Physical Examination Proforma, } \\
\text { Weighing machine, Tape measure. }\end{array}$ & $\begin{array}{l}\text { Bio physical } \\
\text { Assessment }\end{array}$ \\
\hline
\end{tabular}

Table 3 Variables, data collection tools \& techniques of data collection

\section{Results}

Among selected 50 symptomatic perimenopausal patients, majority were in the age group 46 to 50 years(76\%), $70 \%$ below graduate (Table 1) and $70 \%$ were working in associated with health service (Table 2).

Overall $4 \%$ had excellent, $6 \%$ good knowledge whereas $28 \%$ fair and $62 \%$ (31 patients) poor knowledge of osteoporosis. Statistical analysis showed knowledge does not have any association with age (Table 4) and occupation (Table 5) whereas higher education (Higher secondary and above) has association with satisfactory knowledge (Table 6).

\begin{tabular}{|l|l|l|l|l|}
\hline \multirow{2}{*}{$\begin{array}{l}\text { Age } \\
\text { (Years) }\end{array}$} & \multicolumn{2}{|l|}{ Knowledge } & \multirow{2}{*}{$\mathrm{x}^{2}$} & \multirow{2}{*}{ 'p' value of $\mathrm{X}^{2}$} \\
\cline { 2 - 3 } & $<$ Median & $\geq$ Median & \multirow{2}{*}{0.0648} & - \\
\hline$\leq 45$ & 6 & 1 & & - \\
\hline$>45$ & 35 & 8 & \\
\hline
\end{tabular}

With Yates correction, $X 2$ value at $d f(1)=3.84, p>0.05$

Table 4 Association between Age and knowledge of peri menupausal women about osteoporosis and related fractures

\begin{tabular}{|c|c|c|c|c|}
\hline \multirow{2}{*}{ Occupation } & \multicolumn{2}{|c|}{ Knowledge } & \multirow{2}{*}{$x^{2}$} & \multirow{2}{*}{ 'p' value of $x^{2}$} \\
\hline & $<$ Median & $\geq$ Median & & \\
\hline Employed & 22 & 13 & \multirow{2}{*}{1.129} & \multirow{2}{*}{ - } \\
\hline Unemployed & 7 & 8 & & \\
\hline
\end{tabular}

$\mathrm{X}^{2}$ value, at $\mathrm{df}(1)=3.84, \mathrm{p}>0.05$

Table 5. Association between Occupation and knowledge of peri menopausal women about osteoporosis and related fractures. 


\begin{tabular}{|c|c|c|c|c|}
\hline \multirow{2}{*}{ Education } & \multicolumn{2}{|l|}{ Knowledge } & \multirow{2}{*}{$x^{2}$} & \multirow{2}{*}{ ' $p$ ' value of $x^{2}$} \\
\hline & $<$ Median & $\geq$ Median & & \\
\hline$\leq \mathrm{HS}$ & 28 & 7 & \multirow{2}{*}{$7.72^{*}$} & \multirow{2}{*}{-} \\
\hline$>\mathrm{HS}$ & 6 & 9 & & \\
\hline
\end{tabular}

$\mathrm{X} 2$ value, at $\mathrm{df}(1)=3.84^{\star}, \mathrm{p}<0.05,{ }^{*}$ significant, $\mathrm{HS}=$ Higher secondary education

Table 6 Association between education and knowledge of peri menopausal women about osteoporosis and related fractures.

Bone mineral density (BMD) analysis of 31 patients $(62 \%)$ of poor knowledge group showed normal parameter only in two, 18 osteopenic and 11 osteoporotic. Body Mass Index (BMI) analysis of same poor knowledge group of 31 patients, showed normal parameters only in seven patients whereas 24 had abnormal BMI who were distributed as three underweight, nine overweight and 12 obese. Thus, 11 osteoporotic patients who had abnormal BMI carried highest risk of developing fragility fractures. Among 18 osteopenic, 13 with abnormal BMI had moderate and rest 7 normal BMl of which 5 osteopenic and 2 normal BMD had minimal risk

\section{Discussion}

The peri menopausal women are one of the commonest sufferer of osteoporosis \& fragility fracture out of it, thus need special attention to reduce the occurrence of such fractures, associated with not only great financial loss of individual and society but also related with significant mortality and morbidity. Therefore assessment of their knowledge about osteoporosis and fragility fractures and identification of individual of high risk to those were matter of great concern to reduce the risk of such fragility fracture by provision of comprehensive management of osteoporosis.

As per literature support, low percentage of pre and post-menopausal women were aware of osteoporosis and fracture $(16.67 \%$ \& $12.96 \%$ and $30.65 \%$ \& $19.35 \%$ respectively, Nayera E. Hassan et al 2019). We included only symptomatic perimenopausal individual excluding postmenopausal women, as preventive measures are less likely to become successful after menopause(in presence of estrogen deficiency) than before menopause specially when provided to high risk individuals.

In our study, there is significant knowledge deficit irrespective of age \& occupation as there is no association. That indicates there is need to provide the information in widespread strata of society in multiple ways. Present study shows that there is a significant association is present between the knowledge and education. Education even upto graduation is not sufficient enough to have the knowledge of osteoporosis and fragility fracture out of it as suggested by other worker's experiences(Mohammad Reza Etemadifar et al 2013). Significant knowledge deficit (SKD) in $62 \%$ of our samples proves reformation \& improvement of education in multiple ways is urgently needed for definite increase of the knowledge. High priority group has been identified in this significant knowledge deficit(SKD) group, carrying high risk of occurring fragility fracture who need urgent attention.11 patients (22\%) had SKD with osteoporosis(BMD as per DEXA more than -2.5)and abnormal BMI were termed as highest priority group who needed urgent requirement of comprehensive management of osteoporosis.13 patients who had SKD with osteopenia (BMD as per DEXA between - 1 to - 2.5) and abnormal BMl were termed as moderately priority group who carry relative urgency of treatment. Whereas seven patients who had SKD with normal BMI and osteopenia or normal BMD were termed as low priority group who may be kept under observation prior to initiation of comprehensive management of osteoporosis. 


\section{Conclusion:}

The present study concludes that there is significant knowledge deficit among perimenopausal women regarding osteoporosis and resultant fragility fractures irrespective of age and occupation, but associated with lack of conventional education. Analysis of associated factors showed that among the significant knowledge deficit group in majority (62\%) associated osteoporosis and abnormal BMI identifies 11 (22\%) patients of highest priority group who urgently need comprehensive management of osteoporosis to reduce the risk of development of fragility fracture in future.

\section{References}

Kanis J. A., Johnell O., Oden A., Johansson H., Eisman J. A., Fujiwara S., Kroger H., Honkanen R., Melton III L. J., O'Neill T., Reeve J., Silman A., Tenenhouse A. (2006). Tenenhouse The use of multiple sites for the diagnosis of osteoporosis Osteoporosis International, $\quad 17, \quad 527-534$. https://doi.org/10.1007/s00198-005-0014-9

Kanis J.A., Johnell O., De Laet C., et al. (2004). A meta-analysis of previous fracture and subsequent fracture risk. Bone, 35,375.

Melton L.J., 3rd, Atkinson EJ, O'Connor MK, et al. (1998). Bone density and fracture risk in men. 13, 1915.

Mithal A., Bansal B., Kyer C.S., Ebeling P. The Asia-Pacific Regional Audit- Epidemiology, Costs, and Burden of Osteoporosis in India 2013 (2014). A Report of International Osteoporosis Foundation. Indian Journal of Endocrinology and Metabolism. 18(4), 449-54.

\section{Conflicts of Interest}

The authors declare that there are no conflicts of interest regarding the publication of this work.

\section{Acknowledgment:}

The authors are thankful to the Director and Medical Superintendant of Institute of Post Graduate Medical Education and Research, and SSKM Medical College and Hospitals, Kolkata, West Bengal, India for allowing their patients attended in Orthopaedic Outpatient department to perform this study.

Mohammad Reza Etemadifar, SayedMohammadamin Nourian, Mahboobe Fereidan-Esfahani, Hamidreza Shemshaki, Mohsen Nourbakhsh, and Abolghasem Zarezadeh (2013). Relationship of knowledge about osteoporosis with education level and life habits. World J Orthop. 4(3),139-143.

Nayera E. Hassan, Salwa M. El Shebini, Sahar A. El-Masry, Nihad H. Ahmed, Safenaz Y. El Sherity, Enas R. Abd el Hamed, and Heba T. Aboud (2019). Inter - Relationship of Awareness, Knowledge, Attitude, Some SocioEconomic Variables and Osteoporosis in Sample of Egyptian Women. Maced $\mathrm{J}$ Med Sci. 7(15), 2538-2544. 